\title{
Developing intra-curricular photonics educational material for secondary schools in Europe
}

\section{Amrita Prasad, Nathalie Debaes, Robert Fischer, Hugo Thienpont}

Amrita Prasad, Nathalie Debaes, Robert Fischer, Hugo Thienpont, "Developing intra-curricular photonics educational material for secondary schools in Europe," Proc. SPIE 9289, 12th Education and Training in Optics and Photonics Conference, 92890V (17 July 2014); doi: 10.1117/12.2070287

Event: 12th Education and Training in Optics and Photonics Conference, 2013, Porto, Portugal 


\title{
Developing intra-curricular photonics educational material for secondary schools in Europe \\ Amrita Prasad, Nathalie Debaes, Robert Fischer, Hugo Thienpont \\ Vrije Universiteit Brussel, Pleinlaan 2, 1050 Brussels, Belgium; \\ amrita@photonics-explorer.eu
}

\begin{abstract}
There is an imminent shortage of skilled workforce facing Europe's hi-tech industries mainly due to the declining interest of young people in science and engineering careers. To avert this trend the European Union funded the development of the 'Photonics Explorer' - an intra-curricular educational kit designed to engage, excite and educate students about the fascination of working with optics hands-on, in their own classrooms!

Each kit equips teachers with class sets of experimental components provided within a supporting didactic framework based on guided inquiry based learning techniques. The material has been specifically designed to integrate into the curriculum and enhance and complement the teaching and learning of science in the classroom. The kits are provided free of charge to teachers, in conjunction with teacher training courses.

The main challenge of this program was the development of educational material that seamlessly integrates into the various national curricula across Europe. To achieve this, the development process included a preparatory EU wide curricula survey and a special 'Review and Revise' process bringing together the expertise of over 35 teachers and pedagogic experts. This paper reports on the results of the preparatory study which identified two specific age groups at secondary schools for photonics educational material, the didactic content of the Photonics Explorer kit resulting from a pan-European collaboration of key stakeholders, EU wide dissemination and sustainability of the program.
\end{abstract}

Keywords: education, intra-curricular, kit, hands-on, Photonics, didactics, pedagogy

\section{INTRODUCTION}

Scientists and engineers are needed to drive innovation and sustain the technological and scientific growth of high-tech industry worldwide. However, there is an alarming decline of interest towards science prevalent amongst young people. This trend could soon result in a lack of skilled workforce for the high-tech sector and become the primary factor limiting the rapid growth of photonics, like all other scientific sectors [1]. To avert this trend and encourage more young people to experience the fascination of science, the European Commission funded the 'EXPEKT' project in 2010, which resulted in the development of the 'Photonics Explorer' - a novel, intra-curricular, educational kit designed to engage, excite and educate students about the fascination of working with light and optics hands-on, within the classroom.

\section{CONTENT DEVELOPMENT}

Conventional outreach mainly comprises demonstration activities that use interesting visual effects to entertain students. It relies on motivated and enthusiastic scientists and therefore achieves a rather localized and limited impact. While such activities are important to momentarily raise the interest and curiosity of students, they seldom influence their future career choices or image of science as a whole. Therefore it is important to complement such activities with 'educational outreach' that allows students to experience the fun and fascination of scientific discovery on a daily basis - with their own hands, in their own classrooms.

The Photonics Explorer is an intra-curricular kit which has been specifically designed to integrate seamlessly into European secondary school science curricula and enhance and complement the teaching and learning of science within the classroom. The kit consists of a class set of experimental components provided within a supporting didactic framework based on guided Inquiry-Based Learning (IBL) techniques. The content is designed for lower (12-14 years) and upper (16-18 years) secondary students. The kit is a result of a pan-European collaboration of teachers, experts in pedagogy, scientists at universities, industry as well as the extended European photonics community.

12th Education and Training in Optics and Photonics Conference, edited by

Manuel F. P. C. Martins Costa, Mourad Zghal, Proc. of SPIE Vol. 9289, 92890V

(c) 2014 SPIE, OSA, IEEE, ICO · doi: 10.1117/12.2070287

Proc. of SPIE Vol. 9289 92890V-1 


\subsection{Curricula survey and selection of themes for modules}

Teachers in almost all European countries teachers are given educational targets within their curricula which their students have to meet. Most teachers thus have a very fixed time frame that they need to adhere to. Consequently, any additional material or activity which does not directly support the teacher to reach these targets is usually considered as extra-curricular and optional. The Photonics Explorer was specifically designed to integrate into and complement the existing and varying curricula of different European countries. In order to ensure that the content was designed to cover the common basis whilst still maintaining a degree of flexibility, a curricula survey was undertaken.

A questionnaire was designed with the help of teachers in Belgium and France and handed out to science teachers and educational specialists such as teacher instructors or advisors in 10 European countries (Belgium, Czech Republic, Finland, France, Germany, Italy, Poland, Portugal, Spain and the United Kingdom). Together, these countries represent $83 \%$ of the secondary school students of the European member states [3].

The first section of the questionnaire concentrated on the structure of the educational system and the teaching methodology, while the second part focused on the timing of topics in optics and photonics and when they are taught in the curriculum.

The main outcomes on this survey indicated that light and optics are introduced to students at two points during their school career - first in lower secondary (12-14 years) when they are taught the basics of geometric optics (light rays, lenses, reflection, refraction etc.) and second in upper secondary (16-18 years) where they learn about wave optics (diffraction, interference, polarisation etc.). These results directly allowed the determination of the target age group for the development of the Photonics Explorer kit and the crucial points of integration within the different school systems.

In order to determine the modules (topics) to be developed within the kit, an Educational Advisory Panel (EAP) of 35 teachers and experts in pedagogy from $11 \mathrm{EU}$ countries was identified. The panel was given a list of 16 topics (8 for lower secondary level and 8 for upper secondary level) and was asked to vote in order of preference for the topics they would like to see developed in the kit. The top 8 topics were selected; 4 for lower secondary and 4 for upper secondary level.

The modules were developed after carefully surveying the aspects that were already taught within the curriculum, the experiments that were already conducted in schools and the background the students had within each topic. Each module was designed to stand alone, such that it can be easily integrated into the existing curriculum by the teachers. Such a structure gave the teachers the flexibility they needed while increasing the usability and feasibility of the Photonics Explorer within the classroom.

The didactic content is based on guided Inquiry-Based Learning techniques. The Rocard report [2] states that the EU needs a stronger emphasis on the use of inquiry-based learning (IBL) in its classrooms to achieve the goals of a knowledge based society and increase the scientific literacy of its citizens. The didactic framework consists of worksheets, factsheets, notes for the teacher and, where relevant, supporting multimedia material such as photographs or videos.

The modules for Lower secondary level (12-14 years)

- Light signals - the properties of light and its use in telecommunication

- $\quad$ Colours - colour perception, additive and subtractive colour mixing

- $\quad$ Lenses and telescopes - refraction and imaging

- $\quad$ Eye and vision - comparison between human eyes and digital cameras, accommodation in the eye

The modules for Upper secondary level (16-18 years)

- $\quad$ Making light - comparing different light sources, laser

- $\quad$ Polarisation - applications in displays and life sciences

- Diffraction and interference - diffraction on a slit, spectrometry

- A scientist's job - encouraging esp. young women to pursue careers in science and engineering 


\subsection{Review and Revise process}

The modules were designed in an iterative process between the developer team and the EAP reviewers. The 'review and revise' process was especially designed to receive quick and detailed feedback from the EAP reviewers and make the iterative process more efficient. Each module was assigned 3 reviewers $(2$ secondary school teachers and 1 pedagogic expert each from a different EU country). When the first version of the module had been completed by the developer team, the module was sent for a 1st review to the EAP reviewers assigned to that module. The reviewers provide their responses and the didactic content was modified based on this feedback and sent for a 2nd review. This process continued until the module was deemed ready for field tests by both the EAP reviewers and the developer team. It was seen that 2 reviews were generally sufficient for the module to be ready for the classroom.

\section{EXPERIMENTAL COMPONENTS AND DIDACTIC FRAMEWORK}

Each Photonics Explorer kit consists of a class set of experimental components, sufficient for a class of 25-30 students to work in groups of 2-3. The components are robust, versatile and durable and can be used safely in a range of experiments within the classroom.

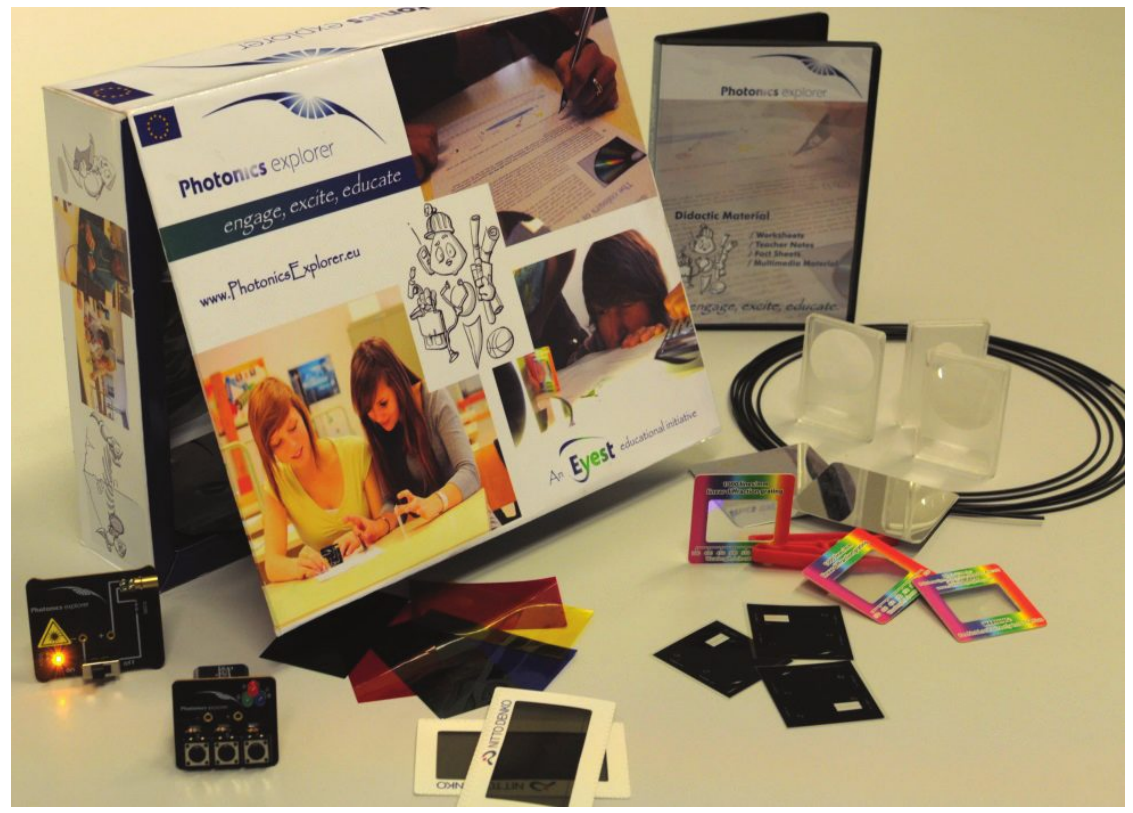

Figure 1: The Photonics Explorer kit

Each module consists of worksheets and factsheets for the students, a comprehensive teacher guide and, where relevant, supporting multimedia material, like pictures and videos that further help to illustrate the concepts. The modular structure allows teachers the flexibility to include and adapt the modules into their unique classroom situations. Each topic is always linked to current technologies thus making the science relevant in the context of students' daily lives.

Worksheets are designed so that students to encourage students to do, observe and reason. Students work in small groups to design their own experimental setups, observe physical effects and then discuss the observed phenomenon, its origin/cause and how such an effect could be useful. They can then directly relate this optical effect to current technologies they encounter in their daily life. For instance, the module 'Light Signals' designed for lower secondary students, poses the problem of ' 3 villages in a valley' that want a more efficient communication system. Students are given a set of criteria that need to be satisfied and thus they learn to come up with solutions, much like in a real engineering situation. Students then encode the alphabet using red, green and blue LEDs (provided in the kit) and communicate a word across classroom using an optical fibre.

The module on 'Polarization' for upper secondary students introduces them to the wave concept of light and makes them observe the effects of crossing two polarizers, inserting a third polarizer (or plastic) between them and looking at their computer or mobile phone screens by rotating a polarizer in front of it. They are then led through the building of a 
'polarimeter' to measure the concentration of a sugar solution using a laser and two crossed polarizers. Finally, the use of polarization in LCDs and industries like pharmaceuticals, sugar industry etc. are explained.

All the didactic material is copyrighted but editable so that teachers can modify the content to suit their needs and classroom situations. The didactic content was also translated into 7 EU languages based on the first 7 countries where the kit was field tested.

\section{FIELD TESTS AND SCIENTIFIC EVALUATION OF IMPACT}

The Photonics Explorer underwent extensive field testing in 7 EU countries from September - December 2011; Belgium, Bulgaria, France, Germany, Poland, Spain and UK. 50 kits were tested, with the content in the local language, with over 1500 students participating in these field tests. Each module was tested in at least 2 classrooms.

The field tests provided the basis for the short and long term scientific evaluation of the impact of the Photonics Explorer in the classroom. IPN in Kiel, Germany was responsible for the scientific evaluation and extensive feedback was collected from all testing students and teachers. The feedback consisted of questionnaires specifically formulated based on the kit. These questionnaires evaluated the students before (pre-test), immediately after (post-test) and a 4-6 months after (follow-up test) working with two or more modules of the Photonics Explorer. This feedback led to the qualitative and quantitative evaluation the impact of the Photonics Explorer. The kit was evaluated in terms of interest of students, self-awareness, image of science and learning progress.

The results of the impact study indicate that the Photonics Explorer indeed increases the self-efficacy of students in those classrooms where IBL techniques are minimal to moderate. It also raises students' interest in Physics especially for weaker and average students (based on a pre-test) and, in particular, also for female students.

\section{DISTRIBUTION AND SUSTAINABILITY}

The Photonics Explorer kit is provided to secondary school teachers completely free-of-charge but only in conjunction with teacher training courses always conducted by local, professional teacher trainers. The teacher training is mandatory to ensure that the fundamentals of implementing inquiry based learning in the classroom are effectively communicated, since IBL demands a change in the role of the teacher in the classroom. It also allows teachers to work hands-on with the material, gain an overview of the didactic content and familiarize themselves with it and ask for clarifications such that the kit is correctly implemented to maximum advantage of students in the classroom.

In order to ensure the long term sustainability of the Photonics Explorer kit, a non-profit organization EYESTvzw has been established. EYESTvzw [Excite Youth for Engineering Science and Technology] is responsible for the assembly and wide distribution of the Photonics Explorer kit [www.eyest.eu]. The kit is assembled in sheltered workplaces in Belgium. The goal of the organization is to raise the interest of young people in science, engineering and technology by creating and dissemination educational programs.

The Photonics Explorer kit is sponsored for schools by European industry, Photonics communities and ministries of education throughout Europe. The successful field tests have already resulted in a demand of at least a hundred additional Photonics Explorer kits in every testing country. The didactic content has already been translated into Czech and additional countries such as Austria, Ireland, Italy, Sweden and the Czech Republic are mobilizing industry and governments to implement the kit in their classrooms.

Over 480 kits have been distributed in 10 EU countries reaching at least 24000 students every year.

\section{REFERENCES}

[1] Gräber W., Nentwig P., Koballa T. and Evans R. (Opladen: Leske +Budrich) "Scientific Literacy. Der Beitrag der Naturwissenschaften zu Allgemeinen Bildung ed chapter Science Literacy: Eine Herausforderung für die Pädagogik", 2002.

[2] Csermely P, Jorde D, Lenzen D, Wallberg-Henriksson H, "Science Education NOW: A renewed pedagogy for the future of Europe", 2007

[3] Education at a Glance 2008: OECD Indicators [http://www.oecd.org/education/skills-beyondschool/educationataglance2008oecdindicators.htm] 